\title{
The Relation between Anemia and Microvascular Complications in Patients with Type 2 Diabetes Mellitus
}

\author{
SAMAR M. YOUSSEF, M.Sc.*; NASRAT M. AYAD, M.D.*; MOHAMMED H. ELBRADEY, M.D.** and \\ NOHA E. ESHEBA, M.D.*
}

The Departments of Internal Medicine* and Ophthalmology**, Faculty of Medicine, Tanta University

\begin{abstract}
Background: Recently, it has been demonstrated that anemia may be an etiological factor in development of microvascular complication in type 2 D.M. patients.

Objective: Evaluation of the relation between anemia and microvascular complications in patients with type 2 diabetes mellitus.

Methods: 100 patients were included in the study. They were selected from wards of Internal Medicine Department and Outpatient Endocrinology Clinic in Tanta University Hospital during the period from February 2016 to August 2016. They divided into two groups, Group (I): 50 patients DM type 2 without anemia. Group (II): 50 patients DM type 2 with anemia $(\mathrm{Hb}$ level $>10 \mathrm{gm} / \mathrm{dl})$. Inclusion criteria: Patients diagnosed to have type 2DM, anemia with ( $\mathrm{Hb}$ level $>10 \mathrm{gm} / \mathrm{dl}$ ) in Group (II). Exclusion criteria: Type 1 DM or other types of diabetes, patients with obvious cause of anemia e.g. hemolytic anemia, aplastic anemia, acute blood loss, severe infection, collagen disease. Chronic illness e.g. severely impaired liver functions (AST or ALT more than 2 upper limit of normal), end stage renal disease. All patients were subjected to: History taking after providing a written informed consent. Full clinical examination including; anthropometric parameters \{weight, height, Body Mass Index (BMI)\}. Upon recruitment, all patients underwent comprehensive assessment of diabetesrelated microvascular complications as following: Diabetic Retinopathy (DR) was assessed by professional ophthalmologists, diabetic nephropathy was assessed according to $24 \mathrm{hr}$ albumin collection in urine. Diabetic peripheral neuropathy was diagnosed by: The presence of typical symptoms and compatible finding from neurological examination or. History of treatment for neuropathy. Laboratory investigations including: Fasting and 2 hour post prandial blood glucose. HbA1C, complete blood count, blood urea, serum creatinine and estimated glomerular filtration rate. 24 hour collection of urine albumin liver function tests. Erythrocyte Sedimentation rate (ESR). C Reactive Protein (CRP) complete iron profile and abdomino-pelvic ultrasound.
\end{abstract}

Results: Comparison between the 2 studied groups showed that $24 \%$ of Group I (DM without anemia) had neuropat hy while $100 \%$ of Group II (DM with anemia) had neuropathy

Correspondence to: Dr. Samar M. Youssef, The Department of Internal Medicine, Faculty of Medicine, Tanta University with statistical significance ( $p$-value $<0.001$ ). Also comparison between the 2 studied groups showed that $26 \%$ of Group I had retinopathy while $100 \%$ of Group II had retinopathy with statistical significance $(p$-value $<0.001)$. The mean of $24 \mathrm{hr}$ ALB which represent diabetic nephropathy in Group I was $(25.10 \pm 4.10 \mathrm{mg} / 24 \mathrm{hr})$ while the mean of it in Group II was (349.26 $\pm 87.67 \mathrm{mg} / 24 \mathrm{hr}$ ). The mean $24 \mathrm{hr}$ ALB in Group II was higher than Group I with statistical significance ( $p$-value $<0.001)$.

Conclusion: Our finding suggests that microvascular complications (diabetic neuropathy, diabetic nephropathy and diabetic retinopathy) were common with anemic patients than the non anemic patients. So we can conclude that anemia may be an etiological factor in development of microvascular complication in type 2 D.M. patients.

Key Words: Anemia - Microvascular complications - Type 2 Diabetes mellitus.

\section{Introduction}

DIABETES is not a single homogeneous disease but composed of many diseases with hyperglycemia as a common feature. Four factors have, historically, been used to identify this diversity: The age at onset, the severity of the disease; i.e. degree of loss of beta cell function, the degree of insulin resistance and the presence of diabetes-associated autoantibodies [1].

Diabetes is a major cause of morbidity and mortality, though these outcomes are not due to the immediate effects of the disorder, they develop as a result of chronic diabetes mellitus. These include diseases of large blood vessels (macro vascular disease) and small blood vessels (micro vascular disease) [1]. Prevalence of micro vascular complications among newly diagnosed patients with DM ranges from 5\% to $35 \%$ [2-5] .

Anemia is one of the complications of DM, particularly in those with overt nephropathy or 
renal impairment. Almost 7\% of outpatients with DM have a Hb level of less than $11 \mathrm{~g} / \mathrm{dl}$ [6,7] .

Chronic anemia results in tissue hypoxia, which is known to play a key role in diabetes associated organ damage. Recent reports have suggested that anemia is one of the risk factors for progression to End-Stage Renal Disease (ESRD) in patients with chronic kidney disease, with or without diabetes [8].

Although chronic kidney disease-induced anemia is more prevalent in patients with Diabetes Mellitus (DM), anemia is a common finding prior to manifestation of kidney disease. In presence of some risk factors at the time of diagnosing DM, microvascular complications must be considered [9].

\section{Patients and Methods}

100 patients were included in the study. They were selected from wards of Internal Medicine Department and Outpatient Endocrinology Clinic in Tanta University Hospital during the period from February 2016 to August 2016.

The patients were divided into two groups:

- Group (I): 50 patients DM type 2 without anemia.

- Group (II): 50 patients DM type 2 with anemia $(\mathrm{Hb}$ level $>10 \mathrm{gm} / \mathrm{dl})$.

\section{Inclusion criteria:}

- Patients diagnosed to have type 2 DM.

- Anemia with (Hb level > 10gm/dl) in Group II.

\section{Exclusion criteria:}

- Type 1 DM or other types of diabetes.

- Patients with obvious cause of anemia e.g. hemolytic anemia, aplastic anemia, acute blood loss.

- Severe infections.

- Collagen diseases.

- Chronic illness e.g. severely impaired liver functions (AST or ALT more than 2 upper limit of normal), end stage renal disease.

\section{All patients were subjected to:}

- History taking after providing a written informed consent.

- Full clinical examination including.

Anthropometric parameters [weight, height, Body Mass Index (BMI)] upon recruitment, all patients underwent comprehensive assessment of diabetes-related microvascular complications as following:

- Diabetic Retinopathy (DR) was assessed by professional ophthalmologists.

- Diabetic nephropathy was assessed according to $24 \mathrm{hrs}$ albumin collection in urine.

- Diabetic peripheral neuropathy was diagnosed by:

1- The presence of typical symptoms and compatible finding from neurological examination.

2- History of treatment for neuropathy.

Laboratory investigations including:

- Fasting and 2 hour post prandial blood glucose.

- $\mathrm{HbA} 1 \mathrm{C} \%$.

- Complete blood count.

- Blood urea, serum creatinine and estimated glomerular filtration rate.

- 24 hour collection of urine proteins.

- Lipid profile: Total cholesterol, Low Density Lipoprotein (LDL), High Density Lipoprotein (HDL) and triglycerides.

- Liver function tests (ALT, AST, T Bil, and S Alb).

- Erythrocyte Sedimentation Rate (ESR).

- C Reactive Protein (CRP).

- Complete iron profile (serum ferritin, transferrin saturation, total iron binding capacity, serum iron).

Radiological finding:

- Abdomino-pelvic ultrasound.

\section{Results}

Comparison between the 2 studied groups showed that $24 \%$ of Group I (DM without anemia) had neuropathy while 100\% of Group II (DM with anemia) had neuropathy with statistical significance $(p$-value $<0.001)$ as shown in (Table 1$)$.

Also comparison between the 2 studied groups showed that $26 \%$ of Group I had retinopathy while $100 \%$ of Group II had retinopathy with statistical significance ( $p$-value $<0.001)$ as shown in (Table 1).

The mean of $24 \mathrm{hr}$ ALB which represent diabetic nephropathy in Group I was $(25.10 \pm 4.10 \mathrm{mg} / 24 \mathrm{hr})$ while the mean of it in Group II was (349.26 \pm 87.67 $\mathrm{mg} / 24 \mathrm{hr}$ ). 
The mean 24hr ALB in Group II was higher than Group I with statistical significance ( $p$-value $<0.001 *$ ) as shown in (Table 2 ).

The mean of $\mathrm{Hb}$ level in Group I was (13.67 \pm $0.75 \mathrm{~g} / \mathrm{dl}$ ) while the mean of it in Group II was $(9.45 \pm 0.31 \mathrm{~g} / \mathrm{dl})$.

The mean $\mathrm{Hb}$ level in Group I was significantly higher than Group II ( $p$-value $\left.<0.001^{*}\right)$ as shown in (Table 3).

This study showed negative correlation with statistical significance between hemoglobin level and duration of diabetes in Group II as shown in Fig. (2).

Roc curve showed $\mathrm{Hb}$ level as prognosis for development of microvascular complications with sensitivity $72.46 \%$ and specificity $100 \%$ as shown in Fig. (3)

Table (1): Comparison between the two studied groups according to diabetic neuropathy and diabetic retinopathy.

\begin{tabular}{|c|c|c|c|c|c|c|}
\hline & \multicolumn{2}{|c|}{$\underset{n=50}{\text { Group I }}$} & \multicolumn{2}{|c|}{$\begin{array}{c}\text { Group II } \\
\mathrm{n}=50\end{array}$} & \multirow{2}{*}{$x^{2}$} & \multirow{2}{*}{$p$} \\
\hline & No & $\%$ & No & $\%$ & & \\
\hline \multicolumn{7}{|c|}{ Diabetic neuropathy: } \\
\hline No & 38 & 76.0 & 0 & 0.0 & $61.290 *$ & $<0.001^{*}$ \\
\hline Yes & 12 & 24.0 & 50 & 100.0 & & \\
\hline
\end{tabular}

Diabetic retinopathy:

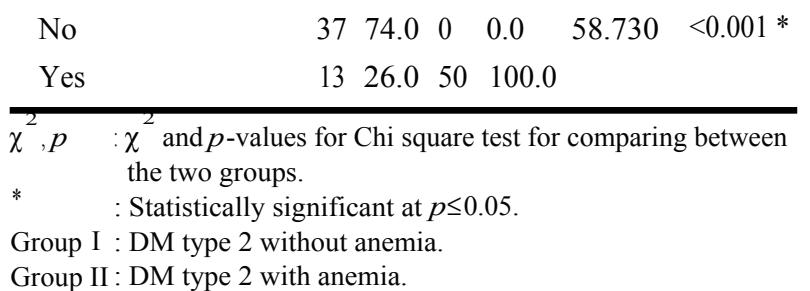

Table (2): Comparison between the two studied groups according to $24 \mathrm{hr}$ ALB (mg/24hr).

\begin{tabular}{cccc}
\hline $\begin{array}{c}\text { Group I } \\
\mathrm{n}=50\end{array}$ & $\begin{array}{c}\text { Group II } \\
\mathrm{n}=50\end{array}$ & $t$ & $p$ \\
\hline
\end{tabular}

\section{$24 h r A L B$}

$(m g / 24 h r)$ :

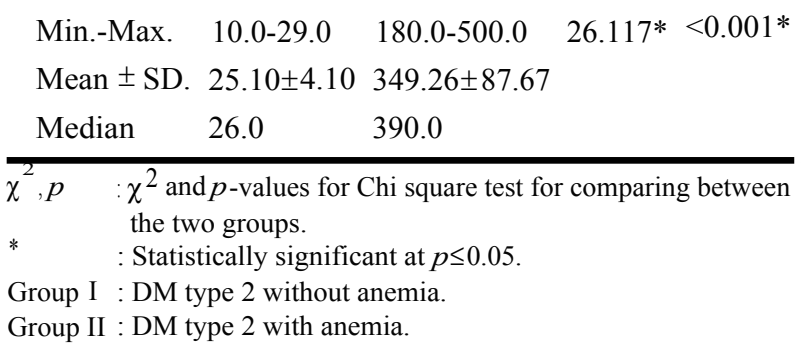

Table (3): Comparison between the two studied groups according to $\mathrm{Hb}(\mathrm{g} / \mathrm{dl})$.

\begin{tabular}{llcll}
\hline CBC & $\begin{array}{c}\text { Group I } \\
\mathrm{n}=50\end{array}$ & $\begin{array}{c}\text { Group II } \\
\mathrm{n}=50\end{array}$ & $\begin{array}{c}\text { Test of } \\
\text { Sig }\end{array}$ & $p$ \\
\hline$H b(g / d l):$ & & & & \\
Min.-Max. & $12.50-15.0$ & $8.90-9.90$ & $t=$ & $<0.001^{*}$ \\
Mean \pm SD. & $13.67 \pm 0.75$ & $9.45 \pm 0.31$ & $36.874^{*}$ & \\
Median & 13.50 & 9.50 & & \\
\hline
\end{tabular}
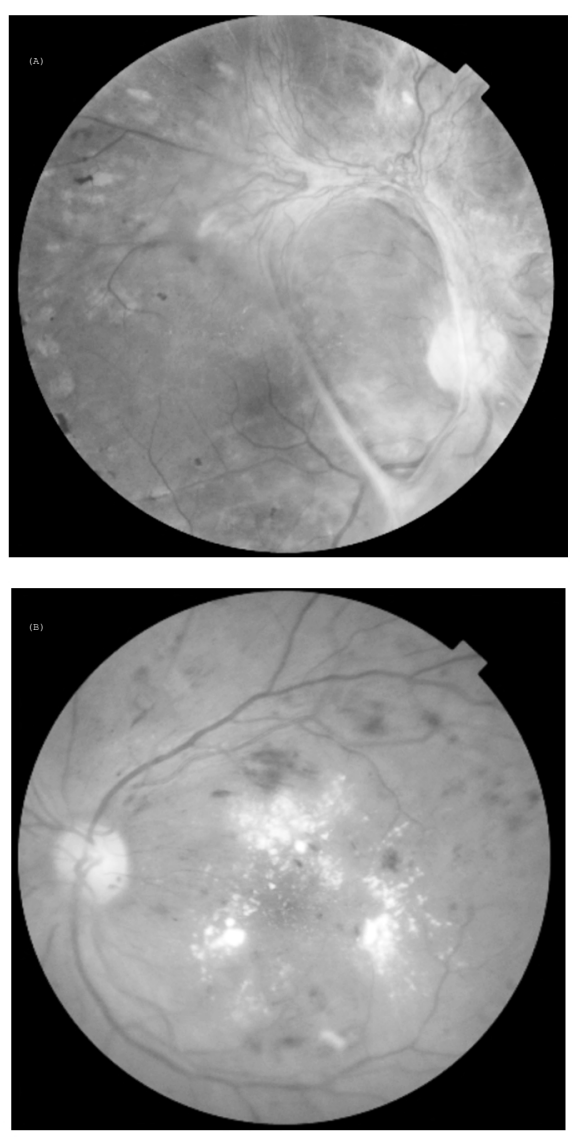

Fig. (1): Fluorescein fundal angiography (A): Proliferative diabetic retinopathy (B) Non proliferative diabetic retinopathy.

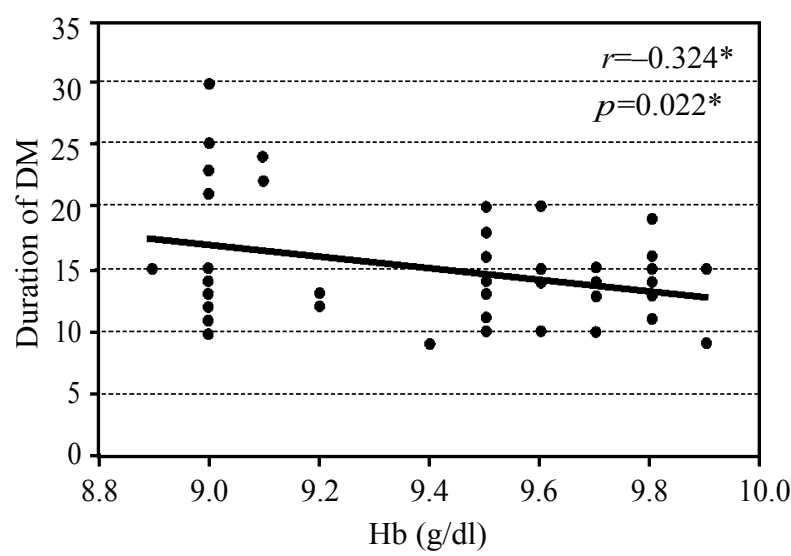

Fig. (2): Correlation between $\mathrm{Hb}(\mathrm{g} / \mathrm{dl})$ and duration of $\mathrm{DM}$ in each group $(n=50)$. 


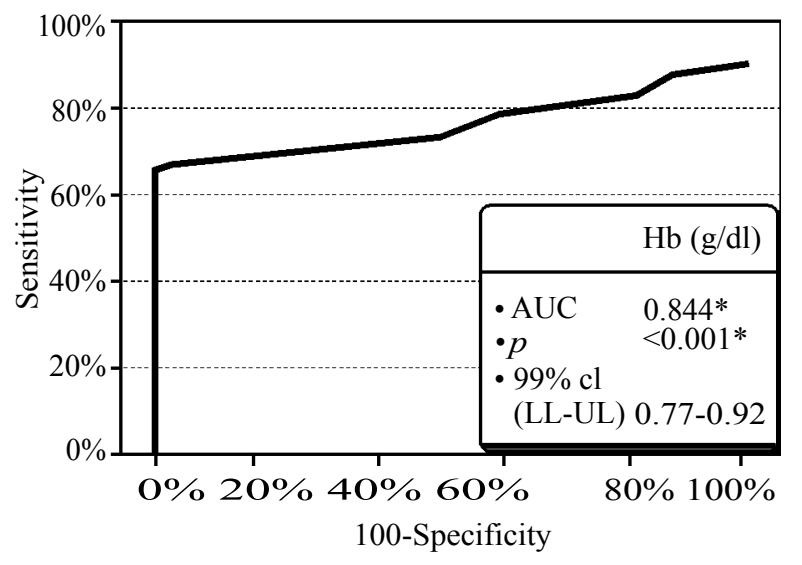

Fig. (3): ROC curve for $\mathrm{Hb}(\mathrm{g} / \mathrm{dl})$ to prognosis development of microvascular complications.

\section{Discussion}

Diabetes is a major cause of morbidity and mortality, though these outcomes are not due to the immediate effects of the disorder, they develop as a result of chronic diabetes mellitus. These include diseases of large blood vessels (macro vascular disease) and small blood vessels (micro vascular disease) [1]. Prevalence of micro vascular complications among newly diagnosed patients with DM ranges from $5 \%$ to $35 \%$ [2-5].

The aim of work was to evaluate the relation between anemia and microvascular complication in patients with type 2 diabetes mellitus. The present work revealed that the mean age was significantly higher in Group II as it was $(60.08 \pm 7.75$ years), in comparison to the mean in Group I, it was $(51.82 \pm 2.35$ years $)$ with $(p$-value $<0.001 *)$.

This was partially in agreement with the results of study performed by Bin-Bin He et al., (2015) [10] as the mean age was significantly higher in diabetic patients with anemia, it was (61.24 \pm 12.06$)$, in comparison to diabetic, non-anemic patients, it was $(56.90 \pm 12.14)$ with $\left(p\right.$-value $\left.<0.001^{*}\right)$. Also the study performed by Govindarajulu et al., [13] . there was a female predominance with no statistical significance.

In this work, there was a slight female predominance, it was (58\%) in Group I, and (66\%) in Group II but not reaching statistical significance $(p$-values $=0.410)$.

This was in agreement with the results of study performed by Barbieri et al., [11] as the two groups, diabetic patients anemic and non-anemic had a female predominance with non statistical significance $(p$-values $=0.059)$.
On the contrary, in the study performed by Bin-Bin $\mathrm{He}$ et al., [10] there was a significant male predominance, they were $(57.1 \%)$ in diabetic patients both; anemic and non-anemic ( $p$-value $<0.001 *$ ), while in the study performed by Govindarajulu et al., [13] there was a female predominance with no statistical significance.

The mean of weight in Group II was (95.04 \pm $8.10 \mathrm{Kg})$ which was significantly higher than Group I $\left(p\right.$-value $\left.=0.023^{*}\right)$.

But other studies only documented BMI not the weight.

The mean BMI of Group II was $(41.70 \pm 5.65$ $\mathrm{kg} / \mathrm{m}^{2}$ ), which was higher than Group I, but with no statistical significance ( $p$-values $=0.675)$, this was partially in agreement with the results of study performed by Hosseini et al., [15] who documented that diabetic and anemic patients had a high BMI than non-anemic (BMI $=28.2 \pm 3.8)$ with no statistical significance.

This was also partially in agreement with the results of study performed by Bin-Bin $\mathrm{He}$ et al., [10] who documented that diabetic and anemic patients had a higher BMI than non-anemic (BMI= $24.86 \pm 3.64)$, but with no statistical significance $(p$-values $>0.05)$.

The mean of height in Group I was (151.78 \pm $2.96 \mathrm{~cm}$ ) while the mean of height in Group II (diabetic and anemic) was $(153.48 \pm 5.77 \mathrm{~cm})$ which was higher than Group I, but with no statistical significance $(p$-value $=0.068)$.

This was partially in agreement with the results of study performed by Barbieri et al., [11] who documented that diabetic and anemic patients were slightly higher than diabetic and non-anemic with mean of height $(161 \pm 8)$ with no statistical significance $(p$-value $=0.287)$.

Comparison between the 2 studied groups showed that $24 \%$ of Group I had neuropathy while $100 \%$ of Group II had neuropathy with statistical significance $(p$-value $<0.001)$.

Also comparison between the 2 studied groups showed that $26 \%$ of Group I had retinopathy while $100 \%$ of Group II had retinopathy with statistical significance $(p$-value $<0.001)$.

The mean of $24 \mathrm{hr}$ ALB in urine which represents (diabetic nephropathy) in Group II was $(349.26 \pm 87.67 \mathrm{mg} / 24 \mathrm{hr})$ which was significantly higher than Group I, $(25.10 \pm 4.10 \mathrm{mg} / 24 \mathrm{hr})$ ( $p$-value $<0.001 *)$. 
Comparison between the 2 studied groups showed that the three microvascular complications (diabetic neuropathy, retinopathy and nephropathy) were much more present and prevalent in Group II (DM with anemia) than Group I (DM without anemia) with statistical significance ( $p$-value $<0.001 *)$.

Regarding to diabetic retinopathy, this was partially in agreement with the results of study performed by Shikha Baisakhiya et al., [16] who documented that anemia was more prevalent with diabetic patients who had DR with statistical significance $(p$-value $<0.001 *)$.

This was partially in agreement with the results of study performed by Bin-Bin He et al., (2015) [10] who documented that $26.4 \%$ anemic patients had microvascular complications and $14.1 \%$ of them had no microvascular complications with statistical significance $\left(p^{\text {-value }}<0.001 *\right)$.

Also this was in agreement with the results of study performed by Govindarajulu et al., [13] who documented that anemic patients had microvascular complications more than the non anemic patients with statistical significance ( $p$-value $<0.05^{*}$ ).

The mean FBS and 2 hours P.B.S in Group II were $(177.98 \pm 11.26 \mathrm{mg} / \mathrm{dL}),(285.36 \pm 24.19 \mathrm{mg} / \mathrm{dL})$ respectively, they were significantly higher than in Group I, $(p$-value $<0.001 *)$.

This was in agreement with the results of study performed by Barbieri et al., [11] who documented that diabetic and anemic patients were significantly more hyperglycemic than diabetic and non-anemic patients $\left(p\right.$-value $\left.=0.005^{*}\right)$.

On the contrary, Thambiah et al., [14] documented that diabetic and non anemic patients were significantly more hyperglycemic than diabetic and anemic patients $(p$-value $=0.026 *)$.

The mean Hb level in Group I $(13.67 \pm 0.75 \mathrm{~g} / \mathrm{dl})$ was significantly higher than Group II (9.45 \pm 0.31 $\mathrm{g} / \mathrm{dl})(p$-value $<0.001 *)$.

This was partially in agreement with the results of study performed by Bin-Bin He et al., [10] who documented that $26.4 \%$ anemic patients had microvascular complications and $14.1 \%$ of them had no microvascular complications with statistical significance $(p$-value $<0.001 *)$.

The mean blood urea and serum creatinine in Group II were $(43.74 \pm 7.69 \mathrm{mg} / \mathrm{dl}),(1.07 \pm 0.16$ $\mathrm{mg} / \mathrm{dl}$ ) respectively, which were significantly higher than in Group I bl ur $(37.02 \pm 4.62 \mathrm{mg} / \mathrm{dl})$, s cr $(0.92 \pm 0.17 \mathrm{mg} / \mathrm{dl})(p$-value $<0.001 *)$.

This was in accordance with the results of study performed by Chellappah Thambiah et al., (2015) [14] who documented that diabetic patients with anemia had significantly high blood urea and serum creatinine ( $p$-value $<0.001 *)$.

The mean of eGFR in Group I (81.32 \pm 17.57$)$ was significantly higher than Group II (64.60 \pm 16.19) ( $p$-value $<0.001 *)$.

This was in agreement with the results of study performed by Bin-Bin He et al., [10] who documented that diabetic patients with anemia and microvascular complications had low eGFR (89.08 \pm 26.19 vs. $98.31 \pm 22.46$ ) than diabetic, non anemic patients with no microvascular complications with statistical significance ( $p$-value $\left.<0.001^{*}\right)$.

Also, Thambiah et al., [14], Hosseini et al., (2014) [15] reported similar results with statistical significance $(p$-value $<0.001 *)$.

The mean of TG, LDL and Cholesterol level in Group II were significantly higher than Group I, they were respectively in Group II (164.72 \pm 15.27 , $157.12 \pm 17.50,243.48 \pm 34.97)$, and in Group I respectively $(142.02 \pm 20.44,151.58 \pm 21.80,203.40 \pm$ $22.98)$ with ( $p$-value $<0.001 *)$.

The mean serum HDL in Group I (65.78 \pm 13.49$)$ was significantly higher than in Group II (50.06 \pm 8.97) $(p$-value <0.001*).

This was partially in agreement with the results of study performed by Bin-Bin He et al., [10] who documented that diabetic patients with anemia and microvascular complications had dyslipidemia (59.8\%) with high TG, LDL, cholesterol level and low HDL than (44.9\%) diabetic, non anemic patients with no microvascular complications with statistical significance $(p$-value $<0.001 *)$.

On the contrary, Barbieri et al., [11] showed disagreement with our result as $46 \%$ of diabeticanemic patients had dyslipidemia, and $48 \%$ of diabetic-non anemic patients had dyslipidemia with no statistical significance $(p$-value $=0.646)$.

Comparison between the 2 studied groups showed that $34 \%$ of Group I were hypertensive while $78 \%$ of Group II were hypertensive with statistical significance ( $p$-value $<0.001 *)$.

This was in agreement with the results of study performed by Bin-Bin He et al., [10] who documented that $63.5 \%$ of diabetic with microvascular 
complications were hypertensive and $48.6 \%$ of diabetic patients with no microvascular complications were hypertensive with statistical significance $(p$-value $<0.001 *)$.

On the contrary, Thambiah et al., [14], documented that $30-40 \%$ of diabetic and anemic patients were hypertensive while $60-69 \%$ of diabetic and non anemic patients were hypertensive but with no statistical significance $(p$-value $=0.644)$.

The mean of duration of DM in Group I was (4.10 \pm 0.58 years) while the mean of it in Group II, it was ( $14.84 \pm 4.56$ years).

The mean of duration of DM in Group II was significantly higher than in Group I ( $p$-value $<0.001 *)$.

This was in agreement with the results of study performed by Hosseini et al., [15] who documented that the mean of duration of DM in diabetic anemic patients was significantly higher than the mean of duration of DM in diabetic patients non anemic patients $(p$-value $<0.05 *)$.

Comparison between the 2 studied groups showed that $74 \%$ of Group I did not have DR and $26 \%$ had proliferative DR while all of Group II had DR with $76 \%$ non-proliferative and $24 \%$ proliferative with statistical significance ( $p$-value $<0.001)$.

This was partially in agreement with the results of study performed by Ranil et al., [12] who documented that individuals with anemia were 1.80 times more likely to develop diabetic retinopathy than individuals with no anemia with statistical significance ( $p$-value $<0.001)$.

The mean HbA1C in group I $(8.92 \pm 0.57 \%)$ was significantly higher than group II $(8.47 \pm 0.54 \%)$ ( $p$-value $<0.001 *)$. II.

This due to the presence of anemia in Group

Thambiah et al., [14] showed partial agreement with our result, as they documented that diabetic and anemic patients had HbA1C (median=7.8) less than diabetic non anemic patients (median=7.9) with no statistical significance $(p$-value $=0.791)$.

Comparison between the 2 studied groups showed that $52 \%$ of Group I were treated with insulin and the others with oral hypoglycemic drugs while $88 \%$ of Group II were treated with insulin and the others with oral hypoglycemic drugs with statistical significance $(p$-value $<0.001 *)$.
This was because Group II patients had uncontrolled blood sugar and microvascular complications which needed insulin to control blood sugar rather than OHDs and this wasn't studied before in other studies.

In Group I, there was no significant statistical correlation between $\mathrm{Hb}$ level and the following (diabetic neuropathy, diabetic retinopathy, type of retinopathy, HTN and type of treatment), also in Group II there was no significant statistical correlation between $\mathrm{Hb}$ level and the following (type of retinopathy, HTN, CRP and type of treatment).

This study showed negative significant correlation between hemoglobin level and duration of diabetes in Group II.

This study showed negative correlation but with no statistical significance between hemoglobin level and $24 \mathrm{hr}$. urinary protein in both groups, s.creatinine in Group II, duration of diabetes in Group I and $\mathrm{HbA} 1 \mathrm{c}$ in Group I.

But Bin-Bin He et al., [10] showed positive correlation with statistical significance ( $p$-value $<0.001 *)$ between anemia and microvascular complications of DM (DR, DR, DPN).

This might be due to the higher cut off value they took for anemia.

This study showed significant negative correlation between hemoglobin level and serum TG in Group I.

This study showed negative correlation but with no statistical significance between hemoglobin level and total cholesterol in both groups, serum TGs in Group II, LDL in both groups.

The ROC curve showed that Hb level had $100 \%$ specificity and $100 \%$ positive PV for development of microvascular complications. This wasn't studied before.

The discrepancies between the results of this work and the result of the other studies may be attributed to differences in case selection criteria of patients and the smaller sample size in this study and the different cut off values for Hb level.

\section{Conclusion:}

Our finding suggests that microvascular complications (diabetic neuropathy, diabetic nephropathy and diabetic retinopathy) were common with anemic patients than the non anemic patients. 
So we can conclude that anemia may be an etiological factor in development of microvascular complication in type 2 D.M. patients.

\section{Competing interests:}

The authors declare that they have no competing interests.

\section{References}

1- ATKINSON M.A., EISENBARTH G.S. and MICHELS A.W.: Type diabetes. Lancet, 383: 69-82, 2014.

2- WOLF G., MULLER N., HUNGER-BATTEFELD W., et al.: Hemoglobin concentrations are closely linked to renal function in patients with type 1 or 2 diabetes mellitus Ws. Kidney Blood. Press. Res., 31: 313-21, 2008.

3- NEW J.R., AUNG T., BAKER P.G., et al.: The high prevalence of unrecognized anemia in patients with diabetes and chronic kidney disease: A population-based study. Diabetes. Med., 25: 564-9, 2008.

4- ADETUNJI O.R., MANI H., OLUJOHUNGBE M., et al.: Microalbuminuric anemia the relationship between haemoglobin levels and albuminuria in diabetes. Diabetes. Res. Clin. Pract., 85: 179-82, 2009.

5- THOMAS M.C., MACISAAC R.J., TSALAMANDRIS C., et al.: Anemia in patients with type 1 diabetes. J. Clin. Endocrinol. Metab., 89: 4359-63, 2004.

6- KDOQI: Clinical Practice Guideline and Clinical Practice Recommendations for anemia in chronic kidney disease: 2007 update of hemoglobin target. Am. J. Kidney. Dis., 50: 471-530, 2007

7- MEHDI U. and TOTO R.D.: Anemia, diabetes and chronic kidney disease. Diabetes. Care, 32: 1320-6, 2009.
8- THOMAS M., TSALAMANDRIS C., MASISAAC R., et al.: Anemia in diabetes: An emerging complication of microvascular disease. Curr. Diabetes. Rev., 1: 107-26, 2005.

9- RAMAN R., GUPTA A., KRISHNA S., et al.: Prevalence and risk factors for diabetic microvascular complications in newly diagnosed type 2 diabetes mellitus. Sanakra Netharlaya Diabetic Retinopathy Epidemiology and Molecular Genetic Study (SN-DREAMS, report 27) J. Diabetes. Complications, 26 (2): 123-8, 2012.

10- BIN-BIN H.E., MIAO X.U., LI WEI, et al.: Relationship between Anemia and Chronic Complications in Chinese Patients with Type 2 Diabetes Mellitus, 18.5: 277-83, 2015.

11- BARBIERI J., FONTELA P., WINKELMANN E., et al.: Anemia in patients with type 2 diabetes mellitus, 2015.

12-PADMAJA K.R., RAJIV R., SUDHIR R.R., et al.: Anemia and diabetic retinopathy in type 2 diabetes mellitus. J. Assoc. Physicians. India, 58: 91-4, 2010.

13- GOVINDARAJULU K.E., MAARAN, et al.: Anemia as a risk factor for microvascular complications in type 2 DM-a cross-sectional study, 2016.

14- THAMBIAH C., SUBASHINI, ELIZABETH GEORGE, et al.: Anemia in Type 2 Diabetes Mellitus (T2DM) patients in Hospital Putrajaya. Malaysian Journal of Medicine and Health Sciences, 11.1: 49-61, 2015.

15- HOSSEINI S., MAHBOOBEH S., SAYYED M., et al.: Anemia and microvascular complications in patients with type 2 diabetes mellitus. Nephro-urology monthly, 64, 2014

16- SHIKHA B., PUNITA G., SURJIT S., et al.: Anemia in patients with type II diabetes mellitus with and without diabetic retinopathy International Journal of Medical Science and Public Health Issue, 2: 305, 2017. 


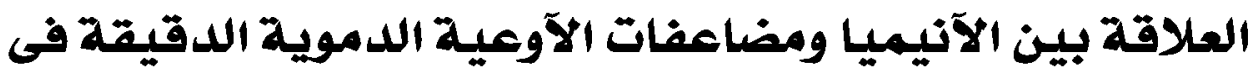 مرضى داء السكر من النوعات الاعو الثانى}

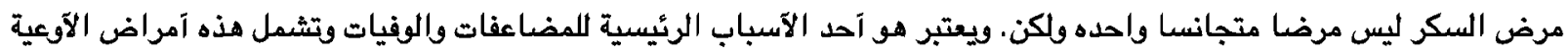

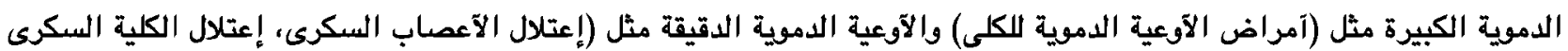

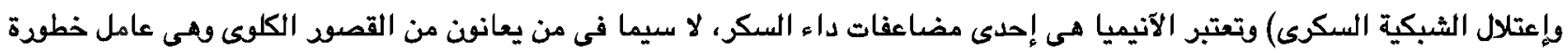

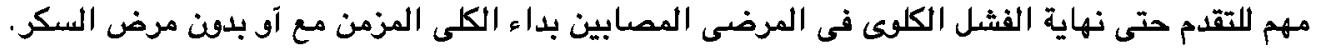

الهدف من البحث :دراسة العلاقة بين الآنيميا ومضاعفات الآوعية الدموية الدقيقة فى مرضى داء السكر من النوع الثانى.

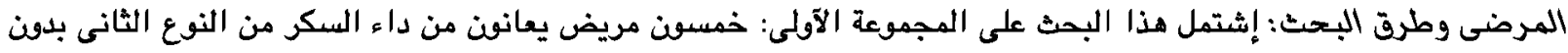

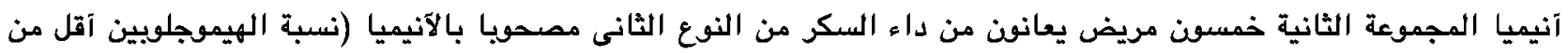

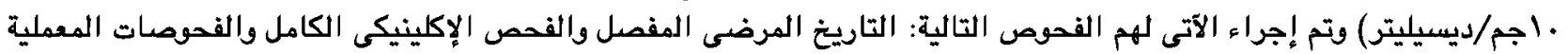

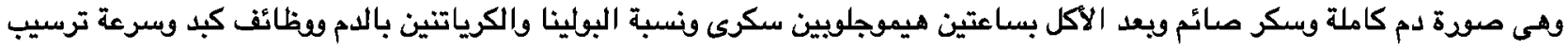

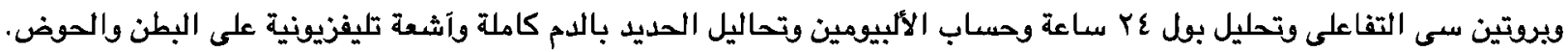
النتائج: آظهرت آن نسبة حدوث مضاعفات الآوعية الدموية الدقيقة وتشمل إعتلال الآعصاب السكرى وإعتلال الكلية السكرى وإعتلال الشبكية كانت أكثر حدوثا في المجموعة الثانية وهم مرضى السكر من النوع الثانى والمصابية الثمن بالآنيميا.

الخلاصة: أوضحت النتائج أن مضاعفات الآوعية الدموية الدقيقة (إعتلال الآعصاب السكرى، إعتلال الكلية السكرى ، إعتلال الشبكية

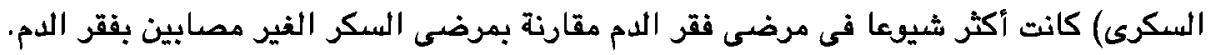

